\title{
LA CLEMENCIA DEL PRÍNCIPE: SU REPRESENTACIÓN ALEGÓRICA EN EMBLEMAS Y EMPRESAS DE ESPAÑA Y AMÉRICA COLONIAL*
}

\author{
Sarissa Carneiro \\ Pontificia Universidad Católica de Chile \\ sarissacarneiro@gmail.com
}

RESUMEN / ABSTRACT

Este ensayo trata la representación de la clemencia como virtud del príncipe en el contexto de las transformaciones políticas que supusieron el progresivo abandono del lenguaje del buen gobierno a favor de la razón de Estado. Se analizan distintas representaciones alegóricas de clemencia y justicia entre los siglos XVI y XVII, en libros de emblemas y empresas políticas españolas y en dos arcos de triunfo novohispanos elevados en 1680.

PALABRAs ClaVe: política católica ibérica, emblemática, relaciones festivas, alegorías de la clemencia.

This investigation deals with the representation of clemency as a Prince's virtue amongst the political transformations which lead to the progressive abandonment of the language of good governance on behalf of the Reason of State. It analyses different allegorical representations of clemency and justice, during the 16th and 17th centuries, in Spanish emblem books and political devices and two triumphal arches raised in 1680's Nueva España.

KEY WORDS: Iberian Catholic politics, emblematics, festive relations, clemency allegories.

Este artículo se enmarca en los proyectos de investigación FONDECYT 11100232 (Inv. Responsable: Sarissa Carneiro) y FONDECYT 1131071 (Inv. Responsable: Constanza Acuña, co-investigadoras: Sandra Accatino y Sarissa Carneiro). 


\section{INTRODUCCIÓN}

En este ensayo, trato la representación de la clemencia como virtud del príncipe en el contexto de las transformaciones políticas que supusieron el progresivo abandono del lenguaje del buen gobierno a favor de la razón de Estado. Particularizo ejemplificando distintas representaciones alegóricas de la clemencia y la justicia entre los siglos XVI y XVII en libros de emblemas y empresas políticas españolas y dos arcos de triunfo elevados en Nueva España en 1680. Me interesa ilustrar, en estos distintos géneros y contextos, los matices y tensiones que se advierten en la política católica hispánica entre la moral cristiana y la cada vez más incisiva ragione di stato. Con ello sigo una línea abierta por autores como Ronald Truman, João Adolfo Hansen y Maurizio Viroli, quienes establecieron importantes precisiones en torno a las distintas tendencias y concepciones del poder en los siglos XVI y XVII en España, Portugal e Italia, así como Pilar Pedraza y Sagrario López Poza, quienes estudiaron sus representaciones emblemáticas a partir del análisis del silencio y del disimulo como virtudes políticas. Este ensayo intenta aportar a esta línea de investigación al tratar otro de los asuntos más controvertidos desde la publicación de El príncipe de Maquiavelo: el manejo de la fuerza y la tensión entre crueldad y piedad, así como entre justicia y clemencia.

\section{LA INSTRUCCIÓN DEL PRÍNCIPE: DEL BUEN GOBIERNO A LA RAZÓN DE ESTADO}

El siglo XVI asiste a notables y decisivas transformaciones en el campo de la política. En términos generales, estas se inscriben en el marco amplio de los cambios sufridos en los modelos de aprehensión de los fenómenos sociales y de la representación del poder, implicados en el paso de una concepción tradicional-que entiende la sociedad como un cuerpo internamente organizado y dotado de un destino metafísico- a un modelo moderno post-cartesiano que refiere los fenómenos sociales a partir de su materialidad puramente externa ${ }^{1}$.

El modelo corporativista, que sostuviera el pensamiento social y político medieval, concebía la sociedad como un cuerpo dotado del poder de auto-

\footnotetext{
Para más antecedentes sobre estas transformaciones en el ámbito ibérico, ver Barreto Xavier, A. y A. M. Hespanha. "A representação da sociedade e do poder".
} 
regulación: el príncipe, en cuanto cabeza de ese cuerpo, representaba la unidad y el equilibro entre los miembros a través del ejercicio de la justicia, definida como la atribución a cada uno de lo que es suyo. En este modelo, el pilar del buen gobierno (comparable al bienestar de un organismo biológico) era la virtud del príncipe, pues de ella devendría el buen manejo de la vida comunitaria.

Esta concepción corporativista, si bien fundada en una metafísica cristiana, daba continuidad a las formulaciones éticas y políticas de la Antigüedad clásica y al concepto del buen gobierno como arte de gobernar con arreglo a los principios de justicia y razón. Esta tradición requería del gobernante la posesión de las virtudes políticas clásicas -la prudencia, la fortaleza, la templanza y la justicia-, un elenco muy ampliado en la Edad Media, llegando a incluir -como en Gil de Roma- la magnanimidad, la liberalidad, la humildad, la veracidad, la afabilidad, la amabilidad, la devoción a Dios y la caridad.

Las profundas transformaciones políticas que llevaron a la crisis de este modelo supusieron, como advirtió Maurizio Viroli, una transición ideológica e intelectual: la política dejaba de ser el arte del buen gobierno para ser razón de Estado, arte del manejo de los medios que permiten conservar el dominio ejercido sobre las gentes o arte de conservar el Estado.

Estas transformaciones suscitaron diversas reacciones. Por un lado, el paulatino desmantelamiento del lenguaje de las virtudes políticas tuvo un desarrollo paralelo a la renovación del ideal ciceroniano de política. Según observa Eugenio Garin, textos como El cortesano de Castiglione guardaban una correspondencia simétrica con obras como El príncipe: en el mismo momento en que la política del príncipe se mostraba más crudamente realista, la filosofía platónica se afirmaba como moda y costumbre, y el cortesano, en cuanto ejecutor de órdenes que provenían no de una norma sino del arbitrio de un hombre (el príncipe), aspiraba a una realidad esencial que fuera reguladora de las cosas y lo trascendiera por dignidad (88).

Asimismo, el abandono de la educación del gobernante ideal y su sustitución por la formación técnico-práctica del "príncipe nuevo" dio lugar a la respuesta incisiva e inmediata de obras como la Utopía de Tomás Moro o Querela pacis e Institutio principis Christiani de Erasmo de Rotterdam, las cuales, sin embargo, parecían refugiar el buen gobierno en el ámbito de una idealidad soñada, de un no-lugar que, a la luz de las transformaciones políticas, devino una aspiración lejana desde el inicio.

Por otra parte, esta arremetida del realismo político tampoco dejó indiferente al mundo católico post-tridentino. La política católica ibérica de los siglos 
XVI y XVII, en el contexto de la disolución de la unidad del cristianismo, se distinguió por la supervivencia del modelo corporativista de una segunda escolástica, adaptado a los fundamentos del poder monárquico. Esta política católica absolutista, en fuerte y directa oposición a Maquiavelo, Lutero, Calvino, Bodin y Tácito, seguirá manteniendo y defendiendo la instrucción del príncipe en las virtudes consideradas indispensables para el adecuado gobierno y la armonía del cuerpo político. Esta instrucción real pretende enseñar el autocontrol y el término medio virtuoso, al tiempo que aspira a confirmar la cima de la jerarquía con la figura del gobernante prudente y discreto $^{2}$.

Sin embargo, es posible advertir entre autores ibéricos de los siglos XVI y XVII (no solo tacitistas, sino incluso antimaquiavelistas más ortodoxos) la incorporación más o menos velada de un arte de Estado. Esta creciente legitimación del lenguaje de la razón de Estado, en tensa convivencia con el viejo discurso del buen gobierno y las renovadas fórmulas del neocorporativismo, se hace evidente en la representación de una virtud como la clemencia, tan cargada de asociaciones clásicas como de profunda raigambre judeocristiana.

\section{CRUELDAD Y CLEMENCIA EN EL PRÍNCIPE NUEVO Y EL PRÍNCIPE CRISTIANO}

Conviene recordar el muy visitado capítulo XVII (De crudelitate et pietate; et an sit melius amari quam timeri, vel e contra) de El príncipe. Como en los demás capítulos que tratan las cualidades del príncipe nuevo, aquí la consideración de la clemencia y de la crueldad refiere siempre a su conveniencia para la conservación del Estado, además de enfocarse primordialmente como un problema de apariencia o de fama, más que de efectivo ejercicio de una virtud. Maquiavelo reconoce que en principio convendría ser considerado clemente y no cruel, pero el príncipe nuevo debe tener en cuenta que la clemencia también puede ser mal usada y que no siempre la fama de crueldad es negativa, pues en ocasiones permite mantener unidos y leales a los súbditos, evitando con el castigo y la fuerza desórdenes, muertes y rapiñas. En algunos

\footnotetext{
Para las particularidades de la instrucción real en Portugal y España, ver respectivamente Hansen, "Educando príncipes no espelho" y Truman, Spanish treatises on Government.
} 
casos, como en operaciones militares, cuando se requiere mantener el ejército unido, la fama de crueldad es especialmente importante.

De estas virtudes, Maquiavelo desprende, además, la conjetura de si es mejor ser amado o temido. La combinación ideal de ambos afectos es muy difícil de lograr, razona el florentino, por cual debe optarse por suscitar el miedo, ya que los vínculos del amor (la gratitud) son mucho más débiles que los sólidos lazos del terror.

Estas recomendaciones se complementan con las también muy conocidas del capítulo siguiente (Quomodo fides a principibus sit servanda), donde Maquiavelo defiende la conjunción de las dos formas de combatir: las leyes, forma propiamente humana, y la fuerza, forma de las bestias. La figura del centauro Quirón, maestro de Aquiles y de otros “príncipes antiguos", preceptor mitad bestia y mitad hombre atestigua la conveniencia de que el príncipe combine estas formas, y que, entre las bestiales, aúna las virtudes del león, capaz de intimidar a los lobos, con las del zorro, capaz de evitar las trampas.

En Institutio principis christiani (1516), texto dedicado al que será luego Carlos V, Erasmo de Rotterdam enuncia una respuesta cristiana a estas transformaciones de la política hacia la razón de Estado. En cuanto tratado de educación del príncipe, no deja de conectarse con las preocupaciones generales de Erasmo, como el rechazo al mundo de las apariencias y la inautenticidad, la necesidad de recuperar un cristianismo primigenio, la crítica a la guerra y la defensa de la paz. Su príncipe cristiano es un príncipe sabio, que además sigue el modelo de Cristo, como padre y no como dueño de sus súbditos. A partir de las clásicas distinciones entre el rey y el tirano, entiende el miedo y el castigo como medios de la tiranía, y el premio y la esperanza como los nervios del Estado del príncipe cristiano. El buen príncipe no debe infundir terror a nadie, excepto a criminales y malhechores a quienes incluso debiera ofrecerse la posibilidad del perdón, en caso de que sean recuperables (Erasmo 37).

Aquí, el semblante del príncipe y del tirano reciben particulares representaciones alegóricas que refieren al mundo animal, en sentidos que se oponen directamente a la figura del príncipe nuevo que combina las virtudes del león y del zorro en la imagen propuesta por Maquiavelo.

En la obra de Erasmo, el león y otras bestias quedan alegóricamente unidos al tirano. Atrayendo a Aristóteles, Erasmo describe esta figura como una enorme y repugnante bestia formada por una mezcla de dragón, lobo y león, con seiscientos ojos, dentada por doquier, temible por sus encorvadas 
uñas y vientre insaciable, ahíta de vísceras humanas, ebria de sangre humana y hostil a todos, especialmente a los buenos (43).

En contraste con esa figura bestial, el príncipe cristiano es representado por Erasmo a partir de una de las analogías de más larga duración desde la Antigüedad, la que compara el príncipe con el rey de las abejas. Haciendo uso de imágenes ya fijadas por Séneca en De clementia, Erasmo destaca que el rey de las abejas se distingue no solo por su particular belleza y volumen, o por andar libre de carga, sino porque siendo todas las abejas tremendamente irascibles, al punto que dejan su aguijón en la herida, solo el rey carece de acúleo: "no quiso la naturaleza que fuese cruel ni que pidiese venganza que había de costarle cara y le quitó el dardo y dejó su ira desarmada. Magnífico ejemplo este para los grandes reyes" (47).

Junto a la autoridad de Séneca, Erasmo recurre a la sabiduría oculta de los jeroglíficos, destacando muy en particular su referencia al cetro de los reyes egipcios que contaban con una cigüeña en la parte más alta y en la más baja, un hipopótamo. Aclara Erasmo que la cigüeña era metáfora de la piedad y el hipopótamo de la fiereza, lo que hacía del cetro una alegoría que cifraba la clemencia venciendo y sofocando en el príncipe eventuales impulsos bestiales, como la crueldad, la ira, los deseos de venganza, la rapacidad o la violencia (76).

Erasmo enuncia entonces una clara amonestación en Institutio principis christiani: nada debe ser procurado con mayor ahínco por el príncipe que ser amado por sus súbditos, lo que se consigue amando a su vez, como hace Dios, que gana a todos para sí a través del bien. La clemencia del príncipe no solo remite a la sabiduría de los antiguos egipcios y de una autoridad como Séneca, sino que adquiere un sentido específicamente cristiano en que el favor del perdón permite la esperanza de compensar los errores de la vida pasada, erigiéndose como virtud primordial del príncipe sabio que imita a Cristo.

Así, en las primeras décadas del siglo XVI, en el seno de estas dos obras paradigmáticas, se fijaban los dos extremos de la cuestión, la cual -en el contexto de una cultura profundamente simbólica, como la llamara Gombrichdeviene inseparable de su representación alegórica.

\section{CLEMENCIA Y JUSTICIA EN LA EMBLEMÁTICA}

La identificación alegórica del príncipe con el rey abeja es reiterada por la emblemática desde su origen: en Emblematum liber (1531), Andrea Alciato presenta la clemencia del príncipe con la imagen de una colmena, coincidiendo 
el emblema CXLVIII Principis clementia (fig.1 y 2) con lo enunciado por Erasmo en su espejo del príncipe cristiano. Reza el epigrama:

Jamás clava el aguijón el rey de las abejas y su cuerpo es el doble de grande que el de las demás. Significa el mando benigno y el Poder moderado, y los santos derechos confiados a los buenos jueces ${ }^{3}$.
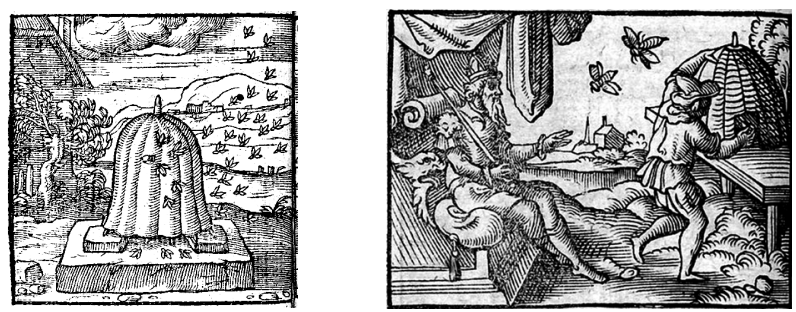

Figs. 1 y 2. Alciato, Emblemata, "Principis clementia" (Leiden, 1591; Frankfurt, 1567)

La idea de que el rey de las abejas carece de aguijón o se exime de usarlo aparece con frecuencia en autores clásicos. Lo refiere Plinio en su Historia Natural (17.52) y Eliano en su Historia de los animales ${ }^{4}$. En De clementia (55 d.C.) de Séneca, la imagen queda definitivamente ligada a la defensa de la clemencia como virtud del príncipe.

La analogía era parte del amplio elenco de atribuciones metafóricas de las abejas en relación con la república y el gobierno: la colmena como ordenada república, ya presente en Platón (República 573 a), fue recogida por Plinio en

3 Cito el epigrama por la traducción de P. Pedraza en la edición a cargo de S. Sebastián.

$4 \quad$ Cito a Eliano: "Hay quienes opinan que las reinas de las abejas carecen de aguijón; otros, por el contrario, creen que estas abejas nacen con aguijones robustos y muy cortantes, que no emplean nunca contra los hombres ni contra las abejas, sino que son recursos para intimidar, porque no sería lícito que el que gobierna y dirige a tantos súbditos les causase algún daño. Y los entendidos en estos menesteres concuerdan en afirmar que las restantes abejas, en presencia de sus gobernantes abaten sus aguijones como renunciando y haciendo cesión de autoridad. Cualquiera quedará impresionado de cada una de las prerrogativas reales ya mencionadas: porque si no poseyesen instrumentos para ofender, esto no sería digno de señalarse; pero si teniéndolos, no lo hacen, esto es mucho más digno de notar (I, 60). Cit. por González de Zárate, Hieroglyphica de Horapolo 200. 
la Historia Natural (XI, V) y en Aristóteles aparece también como ejemplo de la armonía que debiera imperar en toda sociedad (Política, I, I) ${ }^{5}$.

En el emblema CLXXVII de Emblematum liber, cuyo mote es Ex bello pax, unas abejas han hecho su colmena en un yelmo abandonado, figurando alegóricamente la paz: el casco del soldado intrépido, manchado de sangre de los enemigos, sobrevenida la paz, sirve de colmena para las abejas y contiene su grata y rubia miel (fig. 3). Alciato recupera aquí una imagen ya presente en la Antología griega (6.236), la de unas abejas instaladas, en tiempos de paz, en las puntas de las naves de guerra ${ }^{6}$. El emblema le sirve a Alciato para la amonestación: "Yazgan lejos las armas: empréndase sólo la guerra cuando no se pueda gozar de la paz de otra manera" (220).

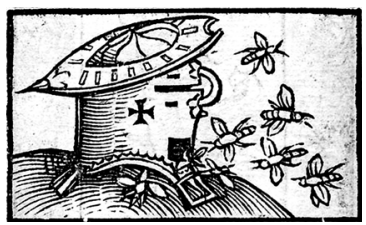

Fig. 3. Alciato, "Ex bello pax" (Augsburg, 1531)

Ahora bien, en el contexto del interés humanista por la sabiduría de los antiguos egipcios, la referencia de Horapolo a la abeja como jeroglífico para "pueblo obediente al rey", añadía ingredientes distintos a los comentados hasta aquí:

Para indicar 'pueblo obediente hacia el rey', pintan una abeja. Pues entre todos los demás animales es el único que tiene rey, al que sigue la restante multitud de abejas, como también los hombres obedecen al rey. Dan a entender a partir de la bondad de la miel y de la fuerza del aguijón del animal que el rey es bondadoso a la vez que enérgico en la justicia y el gobierno (Horapolo, Hieroglyphica 200)

El jeroglífico aportaba una connotación antitética a la alegoría del rey abeja: la bondad de la miel metaforizaba la bondad pero la fuerza del aguijón se comparaba a la energía en la justicia y el gobierno. Este sentido de unión de 
contrarios será reiterado por Valeriano quien comenta que la abeja porta en su cuerpo el veneno como arma a la vez que produce el manjar de la miel ${ }^{7}$.

Este matiz de conjunción de extremos prevalecerá en la emblemática política española, en la que escasamente se encuentra el llamado unívoco a la clemencia tal como enunciado por Erasmo de Rotterdam en Institutio principis christiani.

De hecho, ya la traducción que hace Daza Pinciano del emblema de Alciato sobre la clemencia del príncipe (fig. 4) aporta matices significativos como el énfasis en que, si el rey no tiene aguijón, sí lo tiene su pueblo armado ("que contrasta al enemigo y se apercibe") o la preocupación por la mantención del estado del rey ("Mirad que basta el pueblo estar contento/ para libraros de cualquier engaño/ y para os encumbrar en todo aumento", 224-5).

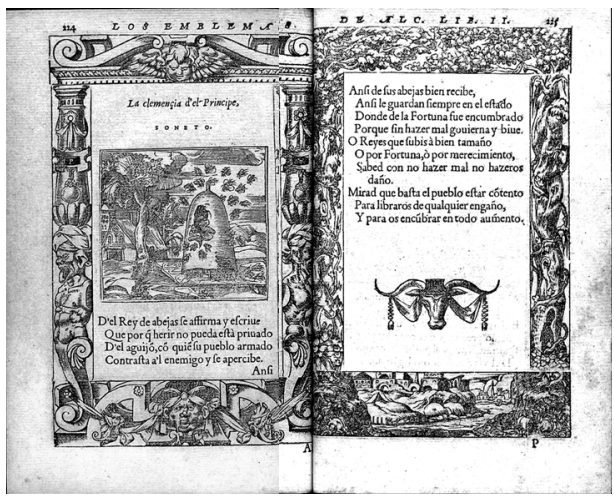

Fig. 4. Los emblemas de Alciato traducidos en rimas españolas (Lyon 1549), "La clemencia del príncipe"

La imagen del rey abeja desaparece luego en los primeros emblemistas españoles. En las Empresas morales (Praga, 1581) de Juan de Borja, la conjunción de justicia y clemencia está figurada por una pictura que remite a la autoridad de Ezequiel $(41,19, \mathrm{~L}, \mathrm{C})$ : una cornisa arquitectónica muestra

Hier. XXXVI, cit. por González de Zárate 201. La abeja como metáfora de la conjunción dolor y dulzura, y en relación con el amor, también en Alciato, emblema CXII, Fere simile ex Theocrito (casi igual que en Teócrito). Para el interés neoplatónico en la unión de contrarios, ver E. Wind, Pagan mysteries in the Renasissance. Para los fundamentos científicos de algunos tópicos asociados a las abejas, ver Quiviger, "Honey from Heaven. Aspects of the Topos of the Bees in Renaissance Artistic Literature". 
una decoración de cabezas de leones y querubines entre palmas enlazadas. El querubín con rostro de león y de hombre alegoriza el medio prudente entre la justicia y la clemencia. El que sabe equilibrar ambas virtudes alcanza la verdadera prudencia y recibe el premio eterno cifrado metafóricamente en las palmas. La empresa tiene como mote Opus prudentiae. La empresa aconseja la conjunción equilibrada y un aristotélico término medio, calificando negativamente ambos excesos: "así como el sumo rigor llega a ser tiranía, así también la demasía en usar misericordia viene a ser remisión y flojedad muy dañosa" (fig. 5).

En los Emblemas morales (Segovia, 1589) de Juan de Horozco, la clemencia tampoco es asociada a la imagen del rey abeja, lo que llama la atención teniendo en cuenta el reconocido senequismo de la obra. En el emblema 16 (libro 2), con el mote Parcere subiectis et debellare superbos, un yugo $\mathrm{y}$ un haz de flechas sobre un pedestal sostienen, en el extremo superior, una corona. La glosa remite a los dichos de Aquiles a su hijo Eneas, cuando en compañía de la Sibila baja al infierno, referidos a que el príncipe romano debe ocuparse de lo que le es propio, es decir, del gobierno público, dejando a los otros pueblos las armas. Juan de Horozco se aprovecha del exemplum para aplicarlo al príncipe en general, quien de acuerdo al emblemista no debe dedicarse a las armas sino mantener la paz y la justicia, destacándose por su sabiduría. Pero para ello el príncipe debe castigar a los insolentes y soberbios y usar la clemencia con los humildes y sujetos, imitando a Dios ("perdonar a los vencidos y combatir a los soberbios").

Con el emblema 30, del libro 3, Juan de Horozco precisa que la acertada aplicación de la justicia conjuga rigor y clemencia. Como reza el epigrama: "No debe ser cruel o justicierol(que dicen), si lo es, en demasíalel rey; que, para serlo verdadero, huye de lo que suena a tiranía.|Tampoco es bien perdone de ligero \lo que de veras castigar debría. QQue no en balde es crecida y coronadalla fruta de agro y dulce sazonada." La glosa remite a la empresa de Enrique IV de las granadas con el mote Dulce agro y recomienda que ni haya exceso en el castigo ni completa falta porque de lo uno nace el odio y de lo otro el menosprecio. Además de la autoridad de Isaías, hace referencia al jeroglífico egipcio que, al igual que en Horapolo, es metáfora de gusto y castigo al mismo tiempo (fig. 6). 


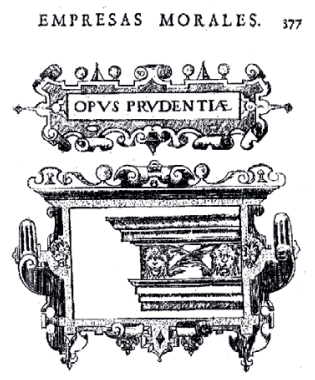

Fig. 5. Juan de Borja, Empresas morales, "Opus prudentiae"

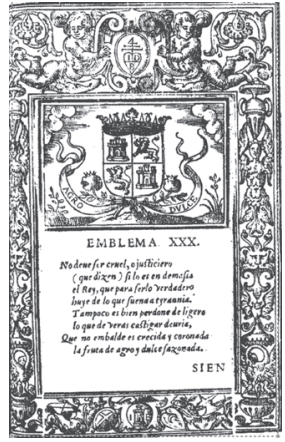

Fig. 6. Juan de Horozco, Emblemas morales, III, 30

Diego Saavedra Fajardo en su Idea de un príncipe político christiano en cien empresas (Munich, 1640; Milán, 1642) aporta formulaciones centrales en el asunto que tratamos. En su introducción a la edición de las Empresas políticas, Sagrario López Poza explica que ya el título mismo de la obra de Saavedra Fajardo puede ser interpretado en relación con las controversias mencionadas en torno a la razón de Estado: la "idea" (edificio político que construye) es de un príncipe "político" y "cristiano" a la vez, respetuoso de la ética cristiana pero asimismo hábil en el arte de la política y la razón de Estado $^{8}$. Saavedra Fajardo intenta conciliar la tradición cristiana y escolástica del pensamiento político con las nuevas tendencias de la razón de Estado, en particular con una inclinación al tacitismo, como camino intermedio que resolvería posibles contradicciones éticas (López Poza, "El disimulo..." 232).

Si bien se proclama antimaquiavélico, Saavedra Fajardo también se muestra contrario a las especulaciones utópicas de repúblicas perfectas: la república perfecta se puede inventar pero no practicar, afirma, porque cualquier gobierno (que es de hombres y no de ángeles) tendrá inconvenientes y aun alguna "especie de tiranía".

$8 \quad$ Cito a Sagrario López: "el título anuncia que lo que se presenta es una traza, un diseño de príncipe paradigmático, modélico, según los preceptos de la complicada política de los nuevos estados, es decir, preparado para ejercer el gobierno, pero sin olvidar los preceptos cristianos que le obligan a considerar la filosofía moral o la ética".

Se cita a Tácito "Delecta ex iis, et consiciata rei publicae forma, laudari facilius quam evenire; vel si evenit, haud diuturna esse potest”. Tac. Ann 4 | 4,33 (Saavedra Fajardo, Empresas políticas 862). 
En muchas empresas, Saavedra Fajardo recurre a la imagen de las abejas como metáfora de la república. Como en el emblema 177 de Alciato, en la empresa 99 de la edición de Milán, Saavedra Fajardo recurre a las abejas para figurar la paz tras la guerra. El yelmo de Alciato aquí es sustituido por un león muerto por Sansón. El mote Merces belli (fig. 7) enfatiza que la recompensa de la guerra es la prosperidad y la abundancia. Pero en otras empresas, Saavedra Fajardo añade a esta difundida metáfora unos sentidos distintos que alertan en torno a sus propias concepciones políticas. En tres empresas, la original asociación metafórica entre abejas/colmena y república armónica sirve más bien a la formulación figurada de la necesidad de la disimulación (empresa 62), a la conveniencia de sofocar las sediciones a tiempo (empresa 73) y de combinar la gravedad con la dulzura en la instrucción del pueblo (empresa 42). Como en el jeroglífico de Horapolo, las abejas metaforizan también la conjunción de la dulzura y la gravedad. Con el mote Omne tulit punctum (Llevó todos los puntos, fig.8), la empresa -basada en una piedra del papa Urbano VIII- recomienda al príncipe que imite a las abejas que con su laboriosidad proporcionan la miel, e instruya al pueblo empleando la dulzura de las diversiones públicas. El arte de reinar consiste en mezclar lo dulce con lo útil, dice Saavedra Fajardo, apropiándose del tópico horaciano. Por medio de la dulzura de luchas, torneos, cañas y otros festejos, el pueblo queda como caballo "que se rinde al halago, y, pasándole suavemente la mano, se deja domar, admite el bocado, y sufre después el peso, la vara y el hierro" (521).

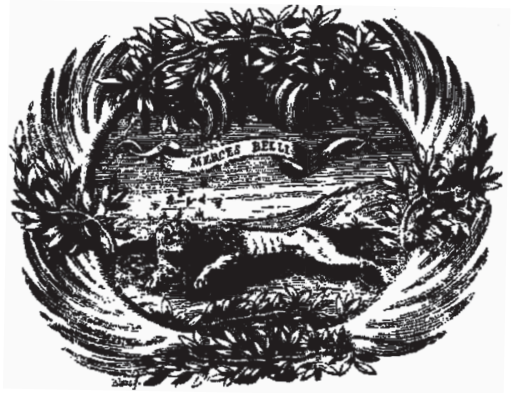

Fig. 7. Saavedra Fajardo, Empresas políticas, empresa 99

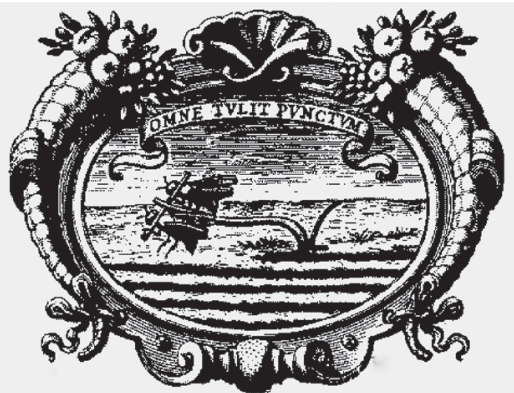

Fig. 8. Saavedra Fajardo, Empresas políticas, empresa 42

El mismo caballo aparece en la empresa 38 que, con el mote "Con halago y con rigor", muestra un potro que inclina su cabeza ante la mano de su domador (fig. 9). Este, a la vez que lo acaricia, porta una vara que lo amenaza. Con la imagen, Saavedra Fajardo incita al príncipe a combinar la severidad y la 
benignidad, para suscitar el amor y el temor. El comienzo de la glosa afirma que la más fiel guarda para el príncipe, su más inexpugnable fortaleza es ser amado. Ese amor es imitación de los vínculos de benevolencia entre los elementos de la naturaleza y de ello es muestra también el rey de las abejas, que carece de aguijón. El difundido tópico es acompañado aquí de otras autoridades como las Partidas de Alfonso el Sabio y exempla históricos, que en su conjunto respaldan el corporativismo neoescolástico ${ }^{10}$. En clara refutación de lo propuesto en El príncipe, Saavedra Fajardo afirma que

muchos príncipes se perdieron por ser temidos, ninguno por ser amado. Procure el príncipe ser amado de sus vasallos y temido de sus enemigos, porque si no, aunque salga vencedor de éstos, morirá en manos de aquéllos (...) el amor y el respeto se pueden hallar juntos. El amor y el temor servil, no. Lo que se teme se aborrece; y lo que es aborrecido no es seguro (488).

A continuación, sin embargo, Saavedra Fajardo matiza que sin temor, el amor se puede convertir en desprecio, haciendo peligrar la autoridad real. Esta afirmación se sostiene en una distinción clave: la del temor que nace de la tiranía y el temor que nace del respeto y la veneración. Evidentemente, Saavedra Fajardo recomienda al príncipe cristiano este último género de temor, así como la disimulación honesta en lugar de la simulación maquiavélica. Pero la distinción pierde fuerza y claridad a la luz de la construcción alegórica de la empresa, reiterada en la glosa: la parte animal del hombre solo se corrige con el temor, por lo que es conveniente que el príncipe dome a los súbditos como se doma a un potro a quien la misma mano que halaga y peina el copete, amenaza con la vara levantada (491). Lo recomendado, entonces, es la conjunción amor y temor: "que le amen porque premia, que le teman porque castiga. (...) Que le amen porque procura la paz, y que le teman porque está dispuesto a la guerra". La conclusión matiza todavía más en un sentido que se aproxima claramente a Maquiavelo: la seguridad del príncipe se funda más en el temor que en el amor, pues este último no está en sus manos y es hijo de la voluntad, inconstante y variable (492).

$10 \quad$ "El cuerpo defiende a la cabeza porque la ama para su gobierno y conservación; si no la amara, no opusiera el brazo para reparar el golpe que cae sobre ella. ¿Quién se expondría a los peligros, si no amase a su príncipe? ¿Quién le defendería la corona?” (487). 
En ese contexto, no sorprende el espacio marginal que tiene la imagen del rey abeja en las Empresas políticas de Saavedra Fajardo. Aquí será otra la alegoría que identifique al rey, la representada en la empresa 22, Praesidia maiestatis (Defensas de la majestad). La pictura de la empresa muestra la simbiosis de dos medias aves, unidas y coronadas: un águila, con los rayos de Júpiter en las garras y un avestruz con una herradura en la boca (fig. 10). Esta simbiosis alegoriza la conjunción conveniente al príncipe cristiano de justicia y clemencia. El príncipe debe tener el estómago del avestruz, que según las historias antiguas era capaz de digerir el hierro, y así ser ardiente en la misericordia. Esta recomendación general está seguida, en la glosa, por precisiones en el manejo de la clemencia que la hacen no tan "ardiente" como proclama el autor: nada hay más dañoso para un príncipe que ser demasiado misericordioso y tan dañosa es para el pueblo la crueldad como la "clemencia desordenada" (376). La clemencia y la severidad deben mezclarse de tal modo que con la justicia el príncipe se haga respetar y con la clemencia, amar. Además de los exempla históricos que apoyan tal recomendación, la misma naturaleza invita a esta "mezcla prudente": "El cielo cría las mieses con la benignidad de sus rocíos, y las arraiga y asegura con el rigor de la escarcha y nieve". El príncipe, vicario temporal de Dios, debe imitar al Creador en ello.

La mayor parte de la glosa refiere, de hecho, a la justicia y no a la clemencia. Las cualidades del águila alegorizan el ejercicio de la justicia: "la agudeza de la vista, para inquirir los delitos; la ligereza de sus alas, para la ejecución; y la fortaleza de sus garras, para no aflojar en ella" (370). En sus garras, los rayos de Júpiter metaforizan el castigo de los excesos. Pero también la aplicación de la justicia debe atender a las distintas circunstancias. Cuando un reino está bien ordenado y hay un vivo temor a la ley, basta que la justicia esté en manos de los ministros. Pero cuando el reino está turbado es conveniente la demostración del ejercicio de la justicia por parte del rey: "que los súbditos vivan recelosos de que puede aparecérseles la mano poderosa del rey, y sepan que, como en el cuerpo humano, así en el reino está en todo él y en cada una de sus partes entera el alma de la majestad" (370).

Saavedra Fajardo tampoco deja sin prescribir aquellos casos en que conviene la disimulación. Cuando los vicios están endurecidos por la costumbre, la justicia aplicada puede parecer crueldad y puede incitar la furia de la muchedumbre irritada. En algunos casos, con disimulación, basta castigar el delito de unos pocos y perdonar a la multitud, o castigar los delitos grandes y perdonar los pequeños. En otros, como las ofensas a su persona o contra la majestad, siempre cabe el castigo, para mantener la columna de la justicia. 


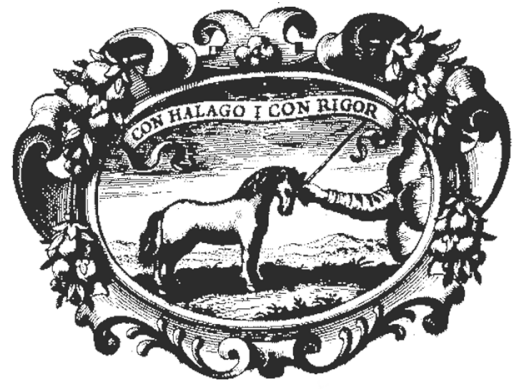

Fig. 9. Saavedra Fajardo, Empresas politicas, empresa 38

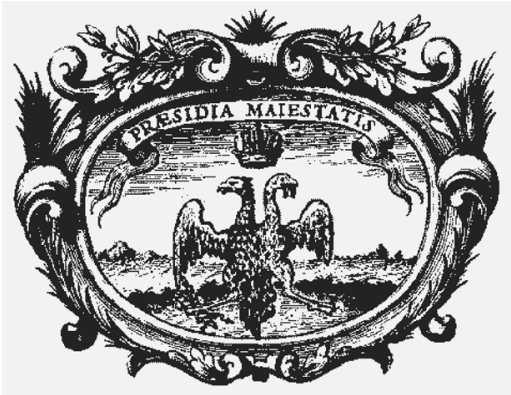

Fig. 10. Saavedra Fajardo, Empresas políticas, empresa 22

Otra circunstancia definitoria es la paz o la guerra: en tiempos de paz conviene la justicia y la clemencia, mientras que, en tiempos de guerra, el premio y el castigo. Según Saavedra Fajardo, los grandes peligros que se enfrentan en la guerra solo se vencen con la esperanza del premio o el temor al castigo. Este último permite que no se aflojen las costumbres de los soldados, lo que ha ocurrido en España, según lamenta el autor. Los delitos de generales deben ser, por el contrario, disimulados, para que no sean víctimas del temor.

Tal casuística del castigo se encuentra también en Príncipe perfecto $y$ ministros ajustados, documentos políticos y morales en emblemas (Lyon, 1642/1662) del jesuita Andrés Mendo ${ }^{11}$. El primer emblema significativo para el tema que tratamos es el 24 con el mote Nullis fraus tuta latebris (E1 delito no queda encubierto por escondrijo alguno). El motivo de la pictura, con un ciervo que se enfrenta a varias serpientes que se asoman por los orificios de una roca, alegoriza el deber del príncipe de limpiar el reino de delincuentes y castigarlos por sus culpas. El castigo limpia a la República del veneno de los delitos y no debe haber cueva que les sirva de sagrado, ni lugar donde no llegue la vara de la justicia. Dar perdón a los culpados es crueldad y no clemencia, y en las culpas graves daña más la disimulación que la severidad.

A este principio general, Mendo añade matices complementarios: recomienda no ejecutar el castigo con aceleración (emblema 28, Cunctandum in poenis),

11 La edición príncipe Lyon, 1642, carecía de imágenes. Cito siempre por la edición impresa en Lyon 1662. 
moderar en ocasiones el rigor de las leyes (emblema 29, Regum Tribunal), aplicar medios suaves antes de llegar a los castigos rigurosos (emblema 30, Temperandum prius quam puniendum), proporcionar los castigos a las culpas (emblema 32, Noxae sit aequa punitio) y perdonar a los enemigos que se rinden (emblema 47).

Pero en el marco de la conjunción justicia y clemencia y su expresión figurada a partir de la alegoría de las abejas, interesan especialmente los emblemas 31 y 33 .

En el emblema 31, Itera culpa gravius punienda (Delitos repetidos no se dejen sin castigos muy severos), un enjambre de abejas ataca a un zángano que intenta alcanzar la copa de un árbol: la indulgencia recomendada en los casos de los primeros delitos se contrapone aquí al castigo riguroso e implacable de los reincidentes. Las abejas atacan el hurto de su dulce trabajo primero con suavidad, desterrando al zángano de su colmena, pero luego responden al delito repetido sin piedad, quitándole a este la vida. Así, el príncipe debe medir su clemencia, porque en "ánimos viles la piedad experimentada engendra atrevimiento", deduce Mendo (154).

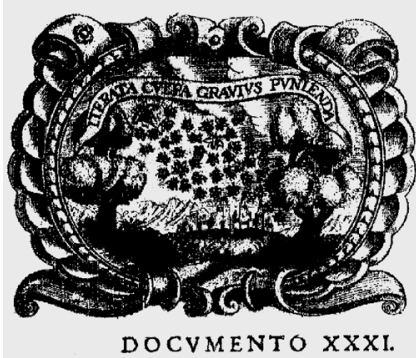

Fig. 11. Mendo, Príncipe perfecto, emblema 31

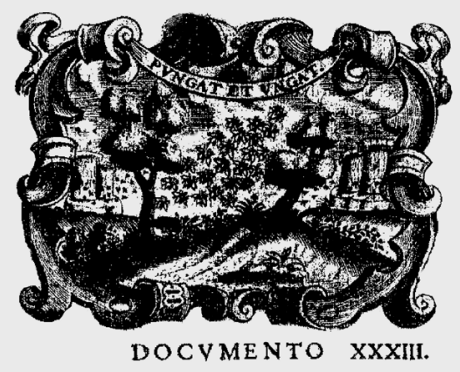

Fig. 12. Mendo, Príncipe perfecto, emblema 33

En el emblema 33, el jesuita recomienda que el príncipe sea justiciero a la vez que piadoso: el mote Pungat et ungat (Pique y unja) acompaña una pictura que representa un enjambre de abejas que sigue a su rey de una colmena a otra para simbolizar el rigor y la clemencia, la mezcla de la miel con el aguijón de la justicia. Explica:

Ni ha de ser todo rigor, ni todo piedad el Príncipe, sean símbolo suyo las abejas, cuya República es la más semejante a la humana en el 
gobierno y en tener Rey que las rige. Forman la miel con dulzura, y en ocasiones con su aguijón castigan severamente. Así se conserva la Corona, castigando y endulzando.

Junto al uso del motivo de la colmena y del rey abeja, en un sentido cercano al formulado por Horapolo, Mendo hace referencia a la granada usada por Enrique IV con el mote SOY AGRIDULCE, como ya hiciera Horozco. El emblema sigue con una exhortación a imitar a Dios, Idea perfectísima de los reyes: el príncipe se acerca a la Divinidad mostrándose compasivo con sus súbditos, pues son propiamente sinónimos Dios y Misericordia. Para el príncipe la clemencia es la más firme fortaleza, el más inexpugnable alcázar, la defensa más segura, porque concilia con ella el amor de los vasallos, cuyas vidas son muros de su vida; el miedo solo provoca el odio y la crueldad no es un freno sino una espuela que incita.

Pero la glosa concluye con la ya consabida fórmula de la clemencia moderada por la justicia. Mendo, aunque refiera a la sinonimia Dios-Misericordia, concluye, como Saavedra Fajardo, que perdonar a todos es como no perdonar a ninguno y que el rey debe tener una balanza que temple la justicia con la misericordia y el castigo con el perdón.

\section{CONSEJO POLÍTICO DESDE AMÉRICA}

Estos asuntos no fueron ajenos a América colonial, donde adquirieron nuevas facetas a la luz de contextos específicos como el debate en torno a las relaciones entre el Viejo y el Nuevo Mundo y las diversas tendencias de la política indiana. Entre los siglos XVI y XVII, el consejo político enunciado desde América, tanto por españoles vinculados a la colonización y a la evangelización como por indios y mestizos, se albergó principalmente en el nutrido conjunto de crónicas, historias y relaciones, géneros que fueron más allá de su vocación principal (es decir, de la narración de acciones y la descripción de lo moral y lo natural) para hacerse cargo de la denuncia de situaciones de injusticia e irregularidades, calificadas de "mundo al revés" o "enfermedades" a las que se recomendaban distintos "remedios", desde una lamentada distancia en relación con la corona. Es el caso de obras centrales como La Florida del Inca (Lisboa, 1605) de Garcilaso de la Vega, la Nueva 
corónica y buen gobierno (1615) de Guamán Poma de Ayala y el Cautiverio feliz (1673) de Francisco Núñez de Pineda y Bascuñán ${ }^{12}$.

Pero en lo que se refiere a la representación alegórica de las virtudes políticas, es la aplicación de la emblemática a las fiestas y celebraciones públicas realizadas en América la principal fuente para su estudio. Me referiré aquí a dos casos especialmente significativos: los arcos de triunfo que Sor Juana Inés de la Cruz y Carlos de Sigüenza y Góngora idearon para la entrada del Virrey Tomás Antonio de la Cerda, Conde de Paredes y Marqués de la Laguna a la ciudad de México, entrada solemne que tuvo lugar el 30 de noviembre de $1680^{13}$.

Ambos arcos han sido objeto de diversos estudios, pero no se ha particularizado todavía la especificidad de su representación de la clemencia y sobre todo no se ha advertido hasta ahora la importancia de dicha virtud para el consejo político que enuncian Sor Juana y Sigüenza y Góngora, lo que gana especial relevancia en el contexto que hemos descrito hasta aquí.

El arco ideado por Sigüenza y Góngora, profusamente explicado por el mismo autor en la relación que tituló Teatro de virtudes políticas, fue encargado por el cabildo y elevado en la entrada de la ciudad, donde se procedió a la ceremonia de entrega de llaves en la plaza de Santo Domingo, junto con la explicación del arco y la lectura de la loa.

El arco construye simbólicamente un "teatro político" fundado en temas frecuentes en los espejos de príncipes así como en emblemas y empresas políticas de la época: el gobierno debe mirar la trascendencia, el príncipe es

12 Véanse, entre otros, los trabajos de R. Adorno sobre la propuesta de buen gobierno de Guamán Poma. Para el caso de Núñez de Pineda y Bascuñán, se han preocupado de precisar su propuesta política Denis Pollard, Lucía Invernizzi y Carmen de Mora, principalmente. En cuanto a La Florida del Inca, he presentado una lectura de esta crónica en clave de consejo político en "La Florida del Inca (1605) de Garcilaso de la Vega: ética y buen gobierno a propósito del cautiverio de Juan Ortiz".

13 Como se sabe, de ambos arcos, en cuanto arquitectura efímera, solo conservamos las relaciones que sus dos ideólogos redactaran. Para las especificidades del género relaciones festivas como emblemática aplicada, remito a: Ledda, G. "Estrategias y procedimientos comunicativos en la emblemática aplicada (fiestas y celebraciones, siglo XVII)" y "Proyección emblemática en aparatos efímeros y en configuraciones simbólicas festivas". Para una descripción del thriumphus como importación borgoñona en España, véase el trabajo de López Poza, "La erudición de Sor Juana Inés de la Cruz en su Neptuno alegórico". Para las distintas dimensiones de la representación en los festejos coloniales, véase Hansen, J. A. "A categoria representação nas festas coloniais dos séculos XVII e XVIII”. 
la ley, pero al mismo tiempo está sometido a la ley, el príncipe debe escuchar los consejos, ideas generales que se complementan con un elenco de virtudes aconsejadas al virrey entrante, la esperanza, la clemencia, la justicia, la prudencia, la devoción y la paz.

En efecto, son ideas frecuentes, pero el edificio es muy singular. Y no solo porque los modelos que presentan estas virtudes al virrey son emperadores aztecas, con marcado énfasis patriótico de parte de Sigüenza (como bien advirtieron estudiosos del arco como Lorente Medina o H. von Kügelgen), sino porque el elenco de virtudes aconseja un tipo de gobierno pacífico, clemente y piadoso, modelo poco usual en el marco del éxito del lenguaje de la razón de Estado.

México solicita al señor marqués de la Laguna la paz para los suyos, dice Sigüenza y Góngora (221) y en un tablero pinta al emperador Tizoc, de quien se dice que sus mismos vasallos, "gente belicosa y sangrienta, le quitaron la vida por ser pacífico" (220). La paz aconsejada en la empresa, aclara Sigüenza, es no solo la contraposición de la guerra, sino la unión de todas las virtudes, sin la cual nada hay agradable a Dios (220-21).

El énfasis en un gobierno pacífico está puesto desde el inicio de la relación, cuando Sigüenza prefiere borrar el carácter militar de la conquista, implícito en el concepto de arco triunfal, proponiendo en cambio la idea de una puerta, que, como observara Lorente Medina, funciona a modo de umbral visual y espiritual, paso iniciático a través del cual el virrey entraría al mundo antiguo de México.

En ese mundo antiguo está Huitzilihuitl, emperador azteca que sirve de espejo de clemencia al conde de Paredes. El tablero pintaba la ciudad de México personificada con rostro alegre y festivo, en sus manos tenía unas tablas que denotaban las leyes, y dos personajes coronaban la ciudad con laureles: el Premio, ideado como muchacho hermosísimo, con sus insignias habituales, y el emperador Huitzilihuitl, "símbolo de la mansedumbre y la clemencia", con unas hermosísimas alas, no dispuestas al vuelo sino recogidas (205). Al fondo, aparecía también el Castigo que se alejaba de la presencia del "clementísimo príncipe" (205).

La alegoría se apoyaba tanto en la iconografía europea como en la historia mexicana, en concreto, en la figura del emperador Huitzilihuitl y el significado de su nombre. Torquemada y Acosta son citados por Sigüenza como fuentes historiográficas que atestiguan que Huitzilihuitl "dejó su república muy bien ordenada con nuevas leyes" y que gobernó con "mucha quietud y paz, siendo muy querido de todos" (205). Como modelo y exemplum histórico, 
Huitzilihuitl personifica el concepto central que anima la empresa, enunciado por el mismo Sigüenza en las primeras líneas de su descripción:

Formar leyes para la dirección de los súbditos es obligación de los príncipes pero el que las observen aquéllos, más que disposición de su arbitrio, es consecuencia de la afabilidad de su trato. No hay armas más poderosas para debelar la protervia humana que la clemencia, cuando asistida de la mansedumbre y el premio introduce en los ánimos de los mortales lo que dictan las leyes para su útil (204).

El concepto es confirmado por muchas autoridades: Claudiano, Valerio Máximo, Plutarco, Suetonio y sobre todo Séneca, De clementia. Algunas citas eruditas aportan los infaltables criterios prácticos de la razón de Estado: con Tácito, recuerda que es útil la fama de clemencia a los que inician un nuevo reino y que es "segurísimo fundamento en que estriba sin temor de ruina el edificio del mando" (204). Pero son referencias minoritarias en una glosa que destaca tanto la sabiduría clásica como el fundamento bíblico y de la tradición cristiana (Salomón en los Proverbios, "Con la clemencia se fortificará su trono", Reyes lib.3 cap. 17, "Si les hablas con palabras blandas, serán tus siervos para siempre”, así como San Gregorio Nacianceno, Hugo de San Víctor y otros).

Especialmente interesante es la forma como Sigüenza adapta la iconografía europea a sus fines. Huitzilihuitl, decíamos, es representado en la pictura con hermosísimas alas recogidas, "no dispuestas al vuelo", "como le faltasen para moverse" (205). La imagen remite al significado del nombre del emperador, "pájaro de estimable y riquísima plumería", como la del pájaro huitzilin (205). Pero la plumería aparece recogida, simbolizando con eso la clemencia, en referencia a una estatua romana de victoria que quedara sin alas por culpa de un rayo. Esta victoria sin alas es mencionada por Ripa como Victoria en la medalla de Tito: desprovista de alas, pues de este modo mostraba Tito su deseo de que la Victoria no se apartara nunca de su lado (401). El mismo Ripa añade que ya así la pintaban los atenienses, como cuenta Pausanias en su Descripción de las Antigüedades de Grecia (401). Pausanias también es recordado por Vicenzo Cartari, quien hace una observación de corte general: "tenevano gli antichi legati alcuni Dei, accioche non partissero da loro", ejemplificando con Apolo y con la Victoria sin alas (337).

Es decir, Sigüenza atrae la metáfora de las alas recogidas para referirse a la clemencia, dando a entender, a partir de las referencias antiguas, que con ello manifiesta su deseo de que la clemencia no abandone a México. La 
alegoría implica, no obstante, obliterar (al igual que en la sustitución del concepto arco por el de puerta) todas las asociaciones bélicas de Victoria. La Victoria de los antiguos, alada o no, tenía como trofeo los despojos de los enemigos, en sus manos portaba lanzas, yelmos o escudos, mientras Huitzilihuitl no está coronado sino que corona a México con su clemencia, acompañado de Premio. Sus armas son muy otras, lo que parece enfatizar con agudeza Sigüenza y Góngora, al emplear un motivo asociado a Victoria para alegorizar, en contraposición, a clemencia.

El segundo arco, ideado por Sor Juana Inés de la Cruz, explicado por extenso en su Neptuno alegórico, también concedía singular importancia a la virtud alabada por Séneca. La entrada de la comitiva a la catedral, para el Te Deum, estuvo precedida por este arco y su explicación en verso. En él, ya no eran los emperadores aztecas sino el dios Neptuno el modelo elegido para el elogio del virrey entrante, vehículo del consejo político enunciado por la monja. Si en Sigüenza una audaz inventio aprovechaba la historia prehispánica para elevar un teatro de virtudes políticas, no menos audaces eran los ejercicios de agudeza que permitían a Sor Juana establecer analogías entre Neptuno y el marqués de la Laguna con miras a transmitirle persuasivamente un paradigma de gobierno.

Este consejo político se desliza con "sutileza cortesana" (como lo llamó Pascual Buxó), en medio de amplificados elogios al virrey entrante y a su esposa, y un extendido uso de complejas argumentaciones y citas eruditas que vienen a respaldar las construcciones alegóricas. El consejo incluye dos recomendaciones muy concretas (proteger la ciudad de México de posibles inundaciones con un adecuado desagüe y concluir las obras de la catedral), pero las demás pinturas del arco (lienzos y jeroglíficos) alegorizan virtudes de un gobernante ideal: en primer lugar, la sabiduría, seguida de la constancia y la prudencia (que proveen seguridad política y social), así como la liberalidad con los buenos consejeros y ministros, y el mando pacífico y clemente.

Este último aspecto es subrayado en dos lienzos, de un total de ocho, lo que da cuenta del relieve que tiene en el contexto general del arco. En ellos se evidencia, además, el manejo discrecional y hasta transgresor que Sor Juana hace de fuentes mitológicas como la Mitología de Natale Conti, con miras a aconsejar este gobierno pacífico y clemente. En el séptimo lienzo, por ejemplo, la pictura representa la conocida competencia entre Neptuno y Minerva para la elección de un nombre para la ciudad de Atenas. En Conti, la fuente es Plutarco en su Temístocles (19,3): Neptuno disputó con Minerva sobre el nombre que había de imponerse a Atenas, ofreciendo él un caballo y 
ella un olivo, saliendo Minerva victoriosa ante los jueces (150). Lo interesante es que Conti atribuye a esta disputa un significado alegórico muy distinto al fijado luego por Sor Juana en su Neptuno. Según Conti, la victoria de Minerva pretendía disuadir a los ciudadanos de la navegación y llamarlos al cultivo de la tierra (154). Sor Juana, que al comienzo de la descripción de este séptimo lienzo, cita explícitamente a Conti ("como lo refiere Plutarco, a quien sigue Natal con toda la escuela mitológica”, 388), lleva la alegoría a un sentido muy distinto: en la competencia, Neptuno hace aparecer el caballo, "despreciando la tierra que le había producido y anunciando guerras con sus sonorosos relinchos" y Minerva con "hermosa oliva" daba "verdes anuncios de paz en sus floridos ramos" (389). La alegoría contrapone guerra y paz; el caballo, insiste Sor Juana, es el símbolo de la parte animal del hombre, por su "innata ferocidad y desasosiego, contrario en todo a la serenidad de la sabiduría", tal como Homero pinta a Marte en un carro tirado por caballos, "para significarlo sanguinolento y furioso" (391). Así, la escena de la disputa entre Neptuno y Minerva sirve a Sor Juana para representar (y aconsejar) la victoria de la sabiduría sobre esa parte animal del hombre, el gobierno ajustado a la sabiduría y a la razón, el gobierno de un príncipe que alcanza el "glorioso vencimiento de sí mismo", es decir, de un príncipe capaz de sujetar la ferocidad y el desasosiego de sus pasiones metaforizadas por el caballo. Para la construcción de este sentido alegórico, Sor Juana presenta a Minerva como engendrada por Neptuno: "que fue de ella vencido, no fue más que decir que se sujetaba a las reglas de la razón que es la verdadera libertad (...) y vencer, como lo hacen todos los sabios, la parte superior del hombre a la inferior, refrenando sus ímpetus desordenados" (390). Así, Sor Juana propone la escena de la disputa entre Minerva y Neptuno como una "doblada victoria", concepto agudo que refiere el mote Dum vincitur, vincit, es decir, vencido, Neptuno vence, porque Minerva, engendrada por él, es su propia sabiduría, la que, además, vence el desordenado ímpetu de las pasiones. Por estas intrincadas vías, Sor Juana llega a borrar los atributos de Neptuno recordados por Conti, su imprudencia y su excesiva crueldad (Conti 155), para representarlo (o desearlo, quizás) sabio como el príncipe ideado por Erasmo, citado, de hecho, al final de la descripción del lienzo (392).

En el lienzo cuarto, se representa una escena siquiera mencionada por Conti: Neptuno defiende y salva a Eneas en combate con Aquiles, nublando la vista de este último con una nube y alzando al aire a Eneas hasta dejarlo a salvo en la retaguardia. La referencia de Sor Juana es el libro V de la Eneida, de la que cita los versos 801-810, en los que Neptuno responde a los ruegos 
de Venus, prometiendo protección a Eneas, como hiciera en el combate con Aquiles en Troya ${ }^{14}$. El emblema festivo ideado por Sor Juana dispone los ejércitos de griegos y troyanos en sangrientos combates, destacando a Eneas salvado por Neptuno del furor de Aquiles. Sat est videat, ut provideat, reza el mote (Basta que vea para que provea), lo que confirma el epigrama: "Por más que Eneas troyano/ tenga a Neptuno ofendido,/ cuando le ve combatido/ le ampara su invicta mano,/ así, Cerda soberano,/ la piedad que os acredita/ ampara al que solicita,/ sin buscar, para razón/ otra recomendación/ que ver que lo necesita" (382).

De este modo, el cruel e imprudente Neptuno de Conti se transforma en sabio y clemente, espejo de príncipe para el Marqués de la Laguna. Sor Juana alegoriza en la escena troyana la clemencia como virtud propia de los príncipes, virtud que antepone la piedad al rigor, tal como aparece en el conocido jeroglífico del cetro con una cigüeña, recordado por la monja: "los egipcios ponían en los cetros y reales insignias, una cigüeña sobre un pie de hipopótamo, animal feroz y cruel, para dar a entender que los príncipes han de anteponer la piedad al rigor; y como ésta nunca campea más que cuando se emplea en el que la merece menos, se puso para explicarlo este mote, Sat est videat, ut provideat" (382). El difundido jeroglífico, mencionado por Horapolo, Valeriano y después Ripa, también había sido atraído -recordemospor Erasmo en Institutio principis christiani (cap. I, 76). La agudeza de la monja jerónima logra, a través de lo que ella misma llama las "sombras de lo fingido" (es decir, la construcción alegórica y fabulosa) insistir en un sentido profundamente cristiano de la clemencia: "nunca campea más que cuando se emplea en el que la merece menos", claro llamado al virrey entrante que, equiparado al grandioso Neptuno, era amonestado sin embargo a refrenar el rigor como muestra de esa "doblada victoria" de la sabiduría y la piedad sobre la pasión y la fiereza.

\section{CONSIDERACIONES FINALES: LA INCISIVA RAZÓN DE ESTADO}

En consonancia con las nuevas concepciones del Estado y del poder, el modelo del príncipe justo y clemente se transforma a la luz de las prescripciones de un manejo discrecional del halago y del rigor. En estas transformaciones 
está en juego el concepto mismo de virtud, ora todavía entendida como esa facultad constante del ánima del rey que asegura el buen gobierno, ora como esa virtù del príncipe que facilita el poder y el éxito político.

$\mathrm{Al}$ analizar distintas representaciones alegóricas de una virtud como la clemencia, observamos el impacto de una cada vez más incisiva razón de Estado, aun en autores que se declaran expresamente contrarios a las prescripciones del realismo político.

En el caso de los libros españoles de emblemas y empresas políticas citados aquí, llama la atención no solo la escasa presencia de la alegoría del rey abeja que carece de aguijón sino sobre todo el hecho de que en muchas empresas la representación figurada (pictura y mote) apunta hacia un predominio de la clemencia (o al menos a un equilibrio entre clemencia y justicia) pero la glosa matiza en sentido contrario, a veces con claros ecos de Maquiavelo, como en algunas empresas de Saavedra Fajardo.

Hacia fines del siglo XVII, dos criollos americanos hacen uso de la tradición emblemática, de la iconografía, la mitología y otras fuentes de erudición para enunciar un consejo político en el que el gobierno pacífico y clemente cumple un rol capital. Con agudeza cortesana y signo patriótico, Sor Juana y Sigüenza cifran la clemencia en figuras alegóricas cargadas de connotaciones opuestas a esa virtud. Es posible, sin embargo, que esta defensa radical de la clemencia como virtud del príncipe nos hable justamente de que los "innumerables espías" de la razón de Estado (como dijera Ripa, al representarla como dama con una túnica llena de ojos y orejas, fig.13) poblaban también los espacios virreinales.

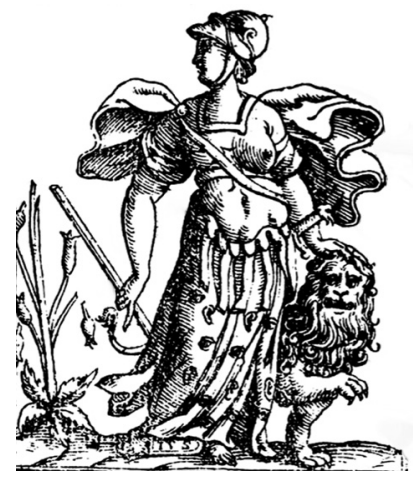

Fig. 13. Razón de Estado en Iconología de Ripa 


\section{BIBLIOGRAFÍA}

\section{FUENTES PRIMARIAS}

Alciato, Andrea. Emblemas. Edición a cargo de Santiago Sebastián. Madrid: Akal, 1985.

Los emblemas de Alciato traducidos en rimas españolas (Lyon, 1549). Ed. Rafael Zafra. Barcelona: Medio Maravedí, 2003.

Borja, Juan de. Empresas morales. Bruselas: Francisco Foppens, 1680.

Cartari, Vicenzo. Le imagini dei i Dei de gli antichi. Lyon, Stefano Michele, 1581.

Conti, Natale. Mitología. Traducción de Rosa María Iglesias Montiel y María Consuelo Álvarez Morán. Universidad de Murcia: Murcia, 1988.

Cruz, Sor Juana Inés de la. Neptuno alegórico. En Obras completas IV. Edición de Alberto G. Salceda. México: FCE, 1957.

Erasmo de Rotterdam, Desiderio. Educación del príncipe cristiano. Trad. Pedro Jiménez y Ana Martín. 2a ed. Madrid: Tecnos, 2007.

Horapolo. Hieroglyphica. Ed. de González de Zárate. Madrid: Akal, 1991.

Horozco, Juan de. Emblemas morales. Zaragoza: Juan de Bonilla, 1604.

Maquiavelo, Nicolás. El príncipe. Trad. Roberto Raschella. Buenos Aires: Losada, 2006.

Mendo, Andrés. Príncipe perfecto y ministros ajustados, documentos politicos y morales en emblemas. Lyon: H. Boissat y G. Remeus, 1662.

Ripa, Cesare. Iconología. Trad. italiano Juan Barja y Yago Barja. Trad. latín y griego Rosa Mariño Sánchez-Elvira y Fernando García Romero. Tomo II. Madrid: Akal, 1987.

Saavedra Fajardo, Diego. Empresas políticas. Ed. Sagrario López Poza. Madrid: Cátedra, 1999.

Sigüenza y Góngora, Carlos de. Teatro de virtudes políticas que constituyen a un príncipe. En Seis obras. Caracas: Biblioteca Ayacucho, 1984. 167-240.

\section{EsTUDIOS}

Adorno, Rolena. Guaman Poma: writing and resistance in colonial Peru. 2nd edition. Austin: The University of Texas Press, 2000.

Barreto Xavier, A. y A. M. Hespanha. "A representação da sociedade e do poder”. José Mattoso (Dir.) História de Portugal. Vol. IV Lisboa: Ed. Estampa, 1993.121-155.

Buxó, Pascual. "Función política de los emblemas en el Neptuno alegórico de Sor Juana Inés de la Cruz". Margo Glantz (Ed.) Sor Juana Inés de la Cruz y sus contemporáneos. México: Universidad Autónoma de México, 1998. 245-255.

Carneiro, Sarissa "La Florida del Inca (1605) de Garcilaso de la Vega: ética y buen gobierno a propósito del cautiverio de Juan Ortiz". Miguel Donoso, Mariela Insúa y Carlos Mata (Eds.) El cautiverio en la Literatura del Nuevo Mundo. Madrid: Iberoamericana Vervuert, 2011. 41-53. 
Garin, Eugenio. "Temi e problemi dela riflessione politica: città reale e città ideale". La cultura del Rinascimento. Milano: Il Saggiatore, 1996. 85-95.

Gombrich, E. H. "Icones symbolicae: The visual Image in Neo-platonic Thought". Journal of the Warburg and Courtauld Institutes 11 (1948): 163-192.

Hansen, J. A. "Educando príncipes no espelho". Floema especial II/2 (2006):133-169.

"A categoria representação nas festas coloniais dos séculos XVII e XVIII". En István Jancsó e Iris Kantor (org.). Festa. Cultura e Sociabilidade na América Portuguesa. Vol. 2 São Paulo: EDUSP/Hucitec, 2001. 735-755.

Invernizzi, Lucía. "Recursos de la argumentación judicial-deliberativa en El cautiverio feliz de Pineda y Bascuñán”. Revista Chilena de Literatura 43 (1993): 5-30.

Kügelgen, Helga von. "La línea prehispánica. Carlos de Sigüenza y Góngora y su Theatro de virtudes politicas que constituyen a un príncipe". Destiempos 3/14 (2008):110-128.

Ledda, Giuseppina. "Estrategias y procedimientos comunicativos en la emblemática aplicada (fiestas y celebraciones, siglo XVII)". En R. Zafra y J. J. Azanza (Eds.). Emblemata Aurea. La emblemática en el Arte y la Literatura del Siglo de Oro. Madrid: Akal, 2000. 251-262.

"Proyección emblemática en aparatos efímeros y en configuraciones simbólicas festivas”. En V. Mínguez (Ed.) Del libro de emblemas a la ciudad simbólica. Actas del III Simposio Internacional de Emblemática Hispánica. Vol. 1. Castellón: Universidad Jaume I, 2000. 361-375.

López Poza, Sagrario. "El disimulo como virtud política en los tratados emblemáticos españoles de educación de príncipes". Estudios sobre literatura emblemática española. Ed. Sagrario López Poza. Ferrol: Sociedad de Cultura Valle Inclán/ Colección SIELAE, 2000. 221-233.

"Introducción". En Empresas politicas de Diego Saavedra Fajardo. Madrid: Cátedra, 1999.

"La erudición de Sor Juana Inés de la Cruz en su Neptuno alegórico". La Perinola 7 (2003): 241-270.

Lorente Medina, Antonio. La prosa de Sigüenza y Góngora y la formación de la conciencia mexicana. México: FCE, 1996.

Mora, Carmen de. Escritura e identidad criollas: modalidades discursivas en la prosa hispanoamericana del siglo XVII. Amsterdam/New York: Rodopi, 2001.

Pedraza, Pilar. "El silencio del príncipe". Goya: revista de arte 187-188 (1985): 37-46.

Pollard, Denis. Rhetoric, politics and the king's justice in Pineda y Bascuñán's Cautiverio Feliz. Universidad de Michigan, 1986.

Quiviger, François, "Honey from Heaven. Aspects of the Topos of the Bees in Renaissance Artistic Literature". En Ulrich Pfisterer y Max Seidel (Eds.) Visuelle Topoi: Erfindung und tradiertes Wissen in den Künsten der italienischen Renaissance. München/Berlin: Deutscher Kunstverlag, 2003.

Truman, R. W. Spanish treatises on Government, Society and Religion in the Time of Philip II. Leiden; Boston; Köln: Brill, 1999.

Viroli, Maurizio. De la politica a la razón de Estado. La adquisición y transformación del lenguaje politico (1250-1600). Trad. Sandra Chaparro. Madrid: Akal, 1992.

Wind, Edgar. Pagan Mysteries in the Renaissance. Middlesex: Penguin Books, 1967. 